\title{
NSW PUBLIC HEALTH NETWORK REPORT ON IMMUNISATION
}

\section{PUBLICATIONS}

Title: Immunisation census of the 1992 school intake in Central and Southern Sydney.

Authors: Goldston K, Bek M, Nixon C.

Publication: NSW Public Health Bulletin 1993; 4:130-131

Contact: $\quad$ CS PHU

Title: $\quad$ A survey of the uptake of Hepatitis B vaccine by health care workers at an Area General Hospital.

Authors: Holt D.

Publication: The Public Health Physician 1993; 4:24

Contact: NS PHU

Title: Undertaking mass Meningococcal vaccination: criteria and experiences.

Authors: Holt D, Hort K.

Publication: Public Health Bulletin 1994; 5; 9:100

Contact: NS PHU

Title: Immunisation Practices of General Practitioners in Metropolitan Sydney.

Authors: Rixon G, March L, Holt D.

Publication: Australian Journal of Public Health 1994; 18 : 258-60

Contact: $\quad$ NS PHU

Title: Hepatitis $B$ vaccination rates among staff at a District General Hospital.

Authors: $\quad$ Stanford M, Black T, March L, Holt D, Campbell D.

Publication: Medical Journal of Australia 1995; 162:304-6

Contact: NS PHU

Title: A retrospective cohort study of childhood immunisation status in Northern Sydney.

Authors: $\quad$ Skinner J, March L.

Publication: Australian Journal of Public Health 1995; 19:58-63

Contact: NS PHU

Title: The integrity of the vaccine cold chain in the Hunter Area of New South Wales.

Authors: Miles TA.

Publication: Australian Journal of Public Health 1993; 17:169-171

Contact: HUN PHU

Title: The capacity of children's services to meet their responsibilities under the Public Health (Amendment) Act 1992.

Authors: Harris E, Harris M, Ferson MJ, Sherry K.

Publication: Australian and New Zealand Journal of Public Health 1996; 20:409-412

Contact: SES PHU

Title: A pilot study of measles immunity in infants aged 4-6 months.

Authors: Ferson MJ, Whybin LR, Robertson PW.

Publication: Communicable Diseases Intelligence 1995; 19:30-31

Contact: SES PHU

Title: Census of school entry immunisation certificates, Eastern Sydney, 1994.

Authors: Ferson MJ

Publication: NSW Public Health Bulletin 1995; 6:9-10

Contact: SES PHU
Title: Another vaccine, another treadmill?

Authors: Ferson MJ.

Publication: Journal of Paediatrics and Child Health 1995; 31:3-5

Contact: SES PHU

Title: Childhood immunisation update.

Authors: Ferson MJ.

Publication: Rattler 1991; 19:19-20

Contact: SES PHU

Title: Immunisation to get a shot in the arm.

Authors: Ferson MJ.

Publication: Australian Doctor 9 September 1994, 40

Contact: SES PHU

Title: Hib vaccination: a guide for health workers.

Authors: Ferson MJ

Publication: Aboriginal and Islander Health Worker Journal 1993; 17(2):13-14

Contact: SES PHU

Title: Immunisation state and its documentation in hospital patients.

Authors: Ferson MJ.

Publication: Paediatrics Digest 1991; 2:6-7

Contact: $\quad$ SES PHU

Title: Measles immunisation compliance: poor impact of Bicentennial measles control campaigns on under-five year olds.

Authors: Ferson MJ, Christie D.

Publication: Australian Journal of Public Health 1992; 16: 31-34

Contact: SES PHU

Title: A survey of immunisation and exclusion policies in centre-based child care.

Authors: Ferson MJ, Christie D.

Publication: Australian Journal of Early Childhood 1991; 16(4):10-14

Contact: $\quad$ SES PHU

Title: Antigenuria following Haemophilus influenzae type b vaccination (letter).

Authors: Ferson MJ, Fisher GT.

Publication: Journal of Paediatrics and Child Health 1993; 29:482-483

Contact: SES PHU

Title: Improving exposure of non-English speaking groups to child immunisation health fairs.

Authors: Ferson MJ, Fitzsimmons GJ.

Publication: Health Promotion Journal of Australia 1992; 2(3):28-31

Contact: SES PHU

Title: School health nurse interventions to increase immunisation uptake in school entrants.

Authors: Ferson MJ, Fitzsimmons GJ, Christie D, Woolett $\mathrm{H}$

Publication: Public Health 1995; 109:25-29

Contact: SES PHU

Title: $\quad$ Cost effectiveness of prevaccination screening of health care workers for immunity to measles, rubella and mumps.

Authors: Ferson MJ, Robertson PW, Whybin LR. 
Publication: Medical Journal of Australia 1994; 160:478-482

Contact: SES PHU

Title: The vaccination status of Aboriginal children in the north-coast region of New South Wales.

Authors: Young M, Taylor L, Beard J, Randall A, Coldwell S.

Publication: Medical Journal of Australia 1994; 161:301-305

Contact: NC PHU

Title: Outbreak of Whooping Cough in the North Coast Region.

Authors: $\quad$ Furber S, Sladden T, Levy M, Beard J.

Publication: NSW Public Health Bulletin 1993; 4:83-4

Contact: $\quad$ NC PHU

Title: Control of Measles in New South Wales (letter).

Authors: Roberts C, Bell J, Capon A.

Publication: Australian Journal of Public Health 1992; 16: 330-331.

Contact: WS PHU

Title: Knowledge of Hib disease and vaccine in long day care centres (letter).

Authors: Bell J, Jorm L, Whitehead P, Capon A.

Publication: Medical Journal of Australia 1993; 158:718

Contact: WS PHU

Title: The epidemiology of incomplete childhood immunization: An analysis of reported immunization status in outer western Sydney.

Authors: Bell JC, Whitehead P, Chey T, Smith W, Capon $\mathrm{AG}$, Jalaludin B.

Publication: Journal of Paediatrics and Child Health 1993; 29:384-388.

Contact: WS PHU

Title: The impact of vaccination against invasive Haemophilus influenzae type $b$ disease in the Sydney region.

Authors: $\quad$ McIntyre P, Chey T, Smith W.

Publication: Medical Journal of Australia 1995; 162:245-8

Contact: WS PHU

Title: Measles outbreak in western Sydney: vaccine failure or failure to vaccinate?

Authors: McDonnell L, Jorm LR and Patel M.

Publication: Medical Journal of Australia 1995;

$162: 471-475$

Contact: WS PHU

Title: School entry immunisation certificates: a useful tool for immunisation surveillance?

Authors: Leckie R, Shah S, Jalaludin B.

Publication: Communicable Diseases Intelligence 1996; 20:6-8

Contact: WS PHU

Title: Tetanus immunity in an older Australian population.

Authors: Heath TC, Smith W, Capon AG, Hanlon M, Mitchell P.

Publication: Medical Journal of Australia 1996; 164:593-596.
Contact: WS PHU

Title: Immunisation coverage of two year old children in childcare centres in the Illawarra and Shoalhaven regions of New South Wales.

Authors: Lloyd G

Publication: Communicable Diseases Intelligence 1996; 20: $217-218$

Contact: ILL PHU

Title: Illawarra Sentinel General Practice Surveillance Network, Sentinel Reporting on Influenza-Like Illness in the Illawarra, New South Wales.

Authors: $\quad$ Lovegrove, D.

Publication: Communicable Diseases Intelligence 1995; 19:420-422

Contact: ILL PHU

\section{REPORTS}

Title: $\quad$ Review of the cold chain in Council immunisation services in Central and Southern Sydney Area Health Services, 1994.

Authors: Goldston K.

Publication: Central Sydney Public Health Unit Source: $\quad$ CS PHU

Title: $\quad$ A survey of hepatitis $B$ vaccination and immunity among health care workers at the Canterbury Hospital, 1995.

Authors: Morrisey J, Bek M.

Publication: Central Sydney Public Health Unit

Source: $\quad$ CS PHU

Title: The vaccine cold chain in the Hunter Area.

Authors: Miles TA.

Publication: Hunter Public Health Unit, Hunter Area Health Service, 1992

Source: HUN PHU

Title: Immunisation rates for Kindergarten children in the South West of NSW, 1992.

Authors: Gilchrist K, Kolbe T.

Publication: South West Centre for Public Health

Source: SW CPH

Title: $\quad$ A study of the vaccine cold chain in the South West Districts.

Authors: Fisher G.

Publication: South West Centre for Public Health

Source: $\quad$ SW CPH

Title: $\quad$ Nurse Immuniser Training Package.

Authors: Ashton L

Publication: South West Centre for Public Health

Source: $\quad$ SW CPH

Title: $\quad$ Review of immunisation status of children attending kindergarten, South East NSW, 1992.

Authors: Sam G.

Publication: South East Public Health Unit

Source: SE PHU 
Title: $\quad$ Surveillance of immunisation rates in Western Sydney and Wentworth Health Areas.

Authors: Conaty S, Jalaludin B, Capon A. Western Sector Public Health Unit.

Source: WS PHU

Title: $\quad$ Report on the 1995 Aboriginal Immunisation Survey - Eurobodalia Area, South Coast New South Wales.

Authors: $\quad$ Sam G, Eldridge R.

Source: SE PHU

Title: Immunisation Coverage in the Southern Tablelands, Monaro and South Coast District of New South Wales, 1995.

Authors: Sam G.

Source: $\quad$ SE PHU

Title: $\quad$ A Model Immunisation Health Outcomes Council Strategic Plan 1995.

Authors: $\quad$ Sam $\mathrm{G}$.

Source: $\quad$ SE PHU

Title: $\quad$ Strategic Plan for Childhood Immunisation in South Western Sydney.

Authors: $\quad$ Division of Population Health, SWSAHS, April 1996

Source: $\quad$ SWS PHU

Title: Evaluation of immunisation outcomes in western NSW.

Authors: Hall JJ, Jane J, Gander C, Phillips A, Chant K, Jump B, Gilbert E.

Source: $\quad$ WN PHU

Title: Compliance with school entry legislation, South West Districts, 1994 (completed).

Source: $\quad$ SW CPH

Title: Evaluation of administration of vaccine through testing for seroconversion.

Source: WN PHU

Title: Evaluation of cold chain and vaccine storage.

Source: WN PHU

Title: $\quad$ Seroprevalence of measles immunity in under five year old NSW children.

Source: $\quad$ SES PHU

Title: Fragmentation of routine immunisation visits among infants receiving hepatitis $B$ immunisation.

Source: $\quad$ SES PHU

Title: Adverse reactions to MMR vaccine in high school children.

Source: $\quad$ SES PHU

Title: Knowledge of Hib disease and vaccine in long day care centres (completed).

Source: WS PHU

Title: The epidemiology of incomplete childhood immunisation: an analysis of reported immunisation status in outer western Sydney (completed).

Source: WS PHU
Title: $\quad$ Survey of tetanus immunisation status in elderly Blue Mountains residents (completed).

Source: WS PHU

Title: $\quad$ Evaluation of cold chain monitoring in hospital and local councils within SWSAHS (completed).

Source: $\quad$ SWS PHU

Title: Immunisation certificate audit - evaluation of compliance with school entry legislation in schools in SWS (1995 and 1996).

Source: $\quad$ SWS PHU

Title: Hib immunisation rates within child care centres within SWSAHS (completed).

Source: SWS PHU

Title: $\quad$ The Vaccine Cold Chain: Vaccine Storage in Pharmacies (completed).

Source: $\quad$ CC PHU

Title: $\quad$ The Vaccine Cold Chain: Vaccine Storage in General Practices.

Source: $\quad \mathrm{CC}$ PHU

Title: "Telling it Right" A Guide on Immunisation for Aboriginal Health Workers.

Source: NC PHU

\section{WORK IN PROGRESS}

Title; $\quad$ Survey of MMR serology in children (underway).

Source: $\quad$ CS PHU

Title: Immunisation cold chain study (underway).

Source: $\quad$ NC PHU

Title: $\quad$ Economic analysis of a mass vaccination campaign to control an outbreak of serogroup $\mathrm{C}$ meningococcal disease.

Authors: Hort K, Jan S, Rixon G.

Publication: Medical Journal of Australia (submitted)

Contact: NS PHU

Title: $\quad$ Survey of immunisation status of 22 month old children in the South East Health Districts (underway).

Source: $\quad$ SE PHU

Title: $\quad$ Survey of recorded immunisation status of children aged between 2 and 3 years. attending pre-school child care centres South East Health Districts (underway).

Source: SE PHU

Title: $\quad$ Survey of immunisation status of Aboriginal children aged 0-5 years South Coast District (underway).

Source: $\quad$ SE PHU

Title: $\quad$ Effectiveness of Hib vaccination (underway).

Source: WS PHU 
TABLE 1

NSW PUBLIC HEALTH UNITS

\begin{tabular}{|lllll|}
\hline Code & Unit & Address & Phone & Facsimile \\
\hline CC PHU & Central Coast Public Health Unit & PO Box 361, GOSFORD NSW 2250 & 043204545 & 043204550 \\
CS PHU & Central Sydney Public Health Unit & PO Box 374, CAMPERDOWN NSW 2050 & 0295153180 & 0295153182 \\
CW PHU & Central West Public Health Unit & PO Box 143, BATHURST NSW 2795 & 063328505 & 063328577 \\
SES PHU & South Eastern Sydney Public Health Unit & Locked Bag 88, RANDWICK NSW 2031 & 0293138322 & 0293136291 \\
HUN PHU & Hunter Public Health Unit & PO Box 466, WALLSEND NSW 2287 & 049246477 & 049246490 \\
ILL PHU & Illawarra Public Health Unit & PO Box 66, KIERAVILLE NSW 2500 & 042264677 & 042264917 \\
NC PHU & North Coast Public Health Unit & PO Box 498, LISMORE NSW 2480 & 066217231 & 066222151 \\
ND PHU & Northern Districts Public Health Unit & PO Box 597, TAMWORTH NSW 2340 & 067662288 & 067663003 \\
NS PHU & Northern Sydney Public Health Unit & Hornsby Ku-ring-gai Hospital, & & \\
& & Palmerston Road, HORNSBY NSW 2077 & 0294779400 & 024821650 \\
SEPHU & South Eastern Public Health Unit & Locked Mail Bag 11, GOULBURN NSW 2580 & 048273428 & 048273438 \\
SW CPH & South West Centre for Public Health & PO Box 503, ALBURY NSW 2640 & 060581700 & 060581701 \\
SWS PHU & South Western Sydney Public Health Unit & Locked Bag 17, LIVERPOOL NSW 2170 & 0298285944 & 0298285955 \\
WN PHU & Western NSW Public Health Unit & PO Box M61, EAST DUBBO NSW 2830 & 068812235 & 068847223 \\
WS PHU & Western Sector Public Health Unit & 13 New Street, NTH PARRAMATTA NSW 2151 & 0298403603 & 0298403608 \\
& & & & \\
\hline
\end{tabular}

\section{PUBLIC HEALTH EDITORIAL STAFF}

The editor of the NSW Public Health Bulletin is Dr Michael Frommer, Director, Centre for Research and Development, NSW Health Department. Dr Lynne Madden is production manager.

The Bulletin aims to provide its readers with population health data and information to motivate effective public health action. Articles, news and comments should be 1,000 words or less in length and include a summary of the key points to be made in the first paragraph. References should be set out using the Vancouver style, the full text of which can be found in British Medical Journal 1988; 296:401-5.

Please submit items in hard copy and on diskette, preferably using WordPerfect, to the editor, NSW Public Health Bulletin, Locked Mail Bag 961, North Sydney 2059. Facsimile (02) 93919029.

Please contact your local Public Health Unit to obtain copies of the NSW Public Health Bulletin.

The Bulletin can be accessed via the Internet from the NSW Health Department's World Wide Website, at

http:/www.health.nsw.gov.au/public-health/phb/phb.html

Back issues can be obtained from the Better Health Centre, Locked Mail Bag 961, North Sydney 2059.

Telephone: (02) 9954 1193, Facsimile (02) 99555196. 